\title{
Genetic alterations and protein expression of KIT and PDGFRA in serous ovarian carcinoma
}

\author{
H Lassus', H Sihto ${ }^{2}$, A Leminen', S Nordling ${ }^{3}$, H Joensuu ${ }^{2}$, NN Nupponen ${ }^{2}$ and R Butzow ${ }^{*}, 1,3$ \\ 'Department of Obstetrics and Gynecology, Helsinki University Central Hospital, Haartmaninkatu 2, Helsinki 00290, Finland; ' ${ }^{2}$ Department of Oncology, \\ Helsinki University Central Hospital, Haartmaninkatu 4, Helsinki 00290, Finland; ${ }^{3}$ Department of Pathology, University of Helsinki, PO Box 21 \\ (Haartmaninkatu 3), Helsinki 000 I4, Finland
}

KIT and PDGFRA are receptor tyrosine kinases that can be specifically inactivated by small-molecule tyrosine kinase inhibitors, notably imatinib mesylate. In ovarian carcinoma, expression of KIT and PDGFRA protein has been documented, but the frequency and the molecular background of expression are poorly known. We analysed the expression of KIT and PDGFRA by immunohistochemistry in 522 serous ovarian carcinomas, and mutations of KIT and PDGFRA by denaturing high-performance liquid chromatographyin I25 and 187 serous ovarian carcinomas, respectively. No mutations of KIT or PDGFRA were detected. KIT expression was detected in 12\% of carcinomas: low expression in 10\% and high expression in 2\% of cases. Using normal serous epithelium as a reference, decreased PDGFRA expression was detected in 12\% and increased expression in 13\% of carcinomas. Both KIT and PDGFRA expression were associated with high tumour grade, high proliferation index and poor patient outcome. By fluorescence in situ hybridisation, no KIT amplification was found in carcinomas with high KIT expression, but two cases showed a relative gain of chromosome 4. In conclusion, no mutations of KIT or PDGFRA were found, but a subset of serous ovarian carcinoma showed overexpression of the proteins, which was associated with aggressive tumour characteristics.

British Journal of Cancer (2004) 9I, 2048-2055. doi:I0.1038/sj.bjc.6602252 www.bjcancer.com

Published online 7 December 2004

(c) 2004 Cancer Research UK

Keywords: ovarian neoplasms; cystadenocarcinoma; serous; KIT; PDGFRA; mutation

Most cases of ovarian carcinoma are disseminated at the time of the diagnosis requiring postoperative chemotherapy. Currently, combination chemotherapy using taxanes and platinum-based drugs is the standard treatment. Initially, majority of the patients respond to treatment, but ultimately over half of them experience disease recurrence and at this phase tumours are frequently resistant to currently used chemotherapy regimens. Thus, more effective treatment options against advanced ovarian carcinoma are needed.

KIT and PDGFRA belong to type III receptor tyrosine kinases, and they can be specifically targeted by tyrosine kinase inhibitors such as imatinib mesylate (STI571) (Fletcher, 2004). Somatic gainof-function mutation of KIT has been documented in several human malignancies, notably acute myelogenous leukaemia, systemic mast cell disease, germ cell tumours and gastrointestinal stromal tumours (GIST) (Heinrich et al, 2002). KIT mutation has a key role in the pathogenesis of GISTs as demonstrated by the clinical effect of imatinib mesylate (Demetri et al, 2002). A subset of GISTs that lack KIT mutation harbour PDGFRA mutations and have shown response to imatinib therapy as well (Heinrich et al, 2003). In addition to point mutations, PDGFRA is activated by other mechanisms such as gene amplification in glioblastoma and chromosomal translocation leading to fusion protein formation in certain myeloproliferative diseases (Fletcher, 2004).

*Correspondence: Dr R Butzow; E-mail: ralf.butzow@hus.fi Received 7 July 2004; revised 12 October 2004; accepted 18 October 2004; published online 7 December 2004
KIT and PDGFRA are not ubiquitous proteins, but their expression has also been reported in some epithelial malignancies including in ovarian carcinoma. This has raised hopes that some carcinomas could be treated with imatinib mesylate. In ovarian carcinomas, the reported frequency of KIT and PDGFRA expression has been highly variable, and little is known about their molecular background and association with clinical parameters (Henriksen et al, 1993; Inoue et al, 1994; Arber et al, 1998; Dabrow et al, 1998; Parrott et al, 2000; Tonary et al, 2000; Schmandt et al, 2003; Singer et al, 2003; Apte et al, 2004a; Matei et al, 2004). GISTs with KIT mutation, particularly in exon 11 , show a clearly better response to imatinib therapy as compared to tumours with no mutation, suggesting that detection of gain-of-function mutation and not solely KIT expression should be a requirement for the treatment (Heinrich et al, 2003).

Ovarian carcinoma is a heterogeneous disease as regards tumour histology. In previous literature, different histological types, mainly serous, mucinous and endometrioid, have been treated as a single entity, but lately they have been shown to differ in their clinicopathological characteristics (Makar et al, 1995; Risch et al, 1996; Heintz et al, 2001) and molecular alterations (Klemi et al, 1995; Tapper et al, 1997; Obata et al, 1998; Lassus et al, 2001; Schwartz et al, 2002). In this study, we have concentrated on one histological type, serous carcinoma, which is the most common subtype of ovarian carcinoma and shows aggressive behaviour and secondary resistance to currently used adjuvant therapy.

To evaluate the molecular basis for use of imatinib mesylate in ovarian carcinoma, we analysed the frequency of KIT and PDGFRA 
mutations by denaturing high-performance liquid chromatography (DHPLC) and direct sequencing of aberrant exons in 125 and 187 serous ovarian carcinoma specimens, respectively. Protein expression status of KIT and PDGFRA was performed by immunohistochemistry of tissue microarray containing 522 serous ovarian carcinomas. Tumours showing aberrantly high expression of KIT were further tested for KIT amplification by fluorescence in situ hybridisation (FISH). The findings were correlated with clinicopathological and other molecular characteristics of the tumours and outcome of the patients.

\section{MATERIALS AND METHODS}

\section{Mutation analysis}

Tumour samples were obtained from patients undergoing primary surgery for ovarian carcinoma at the Department of Obstetrics and Gynecology, Helsinki University Central Hospital. Tumours with serous histology and tumour cell percentage over 60 (range 60-95, median $75 \%$ ) were included in the study. Borderline tumours were excluded from the study, but otherwise the cases were not selected for stage or grade. KIT mutation analysis was performed from 111 fresh-frozen and from 14 paraffin-embedded samples, and PDGFRA mutation analysis from 187 fresh-frozen tumour samples. DNA was extracted from tumour tissue block after mechanical disruption directly (fresh-frozen samples) or after xylene extraction (paraffin-embedded samples). A standard proteinase-K-phenol-chloroform method was used for DNA extraction.

\section{PCR conditions for mutational analysis}

Exons of 9,11, 13 and 17 of KIT and exons 11 and 17 of PDGFRA (according to the Human Genome Project available at http:// www.ensembl.org; exons 11 and 17 correspond to PDGFRA exons 12 and 18 of GenBank Accession number D50013, http:// www.ncbi.nlm.nih.gov:80/entrez/) were amplified from tumour samples using primers given in Table 1 . PCR was performed in $50 \mu \mathrm{l}$ reactions consisting of $20-50 \mathrm{ng}$ genomic DNA, $0.2 \mathrm{~mm}$ dNTPs, $1 \times$ PCR buffer (Gibco BRL, Gaithersburg, MD), $4.5 \mathrm{~mm}$ $\mathrm{MgCl}_{2}, 0.5 \mathrm{U}$ Platinum Taq DNA polymerase (Gibco BRL), $0.5 \mathrm{U}$ AmpliTaq Gold (Applied Biosystems) and $10 \mathrm{pmol}$ of each forward and reverse primer (Gibco BRL). PCR cycles consisted of $95^{\circ} \mathrm{C}$ for $14 \mathrm{~min}$, followed by 35 cycles of $30 \mathrm{~s}$ at $95^{\circ} \mathrm{C}, 30 \mathrm{~s}$ at $55^{\circ} \mathrm{C}$ for exons of $K I T / 59^{\circ} \mathrm{C}$ for exons of PDGFRA, $45 \mathrm{~s}$ at $72^{\circ} \mathrm{C}$ and a final extension at $72^{\circ} \mathrm{C}$ for $5 \mathrm{~min}$. Subsequently, the PCR fragments were analysed with DHPLC.

\section{Denaturing high-performance liquid chromatography}

PCR products were denatured for $3 \mathrm{~min}$ at $95^{\circ} \mathrm{C}$ and then reannealed gradually over $30 \mathrm{~min}$ using a $95^{\circ} \mathrm{C}$ to $40^{\circ} \mathrm{C}$ temperature gradient. The optimal melting temperature for each PCR amplicon was obtained by analysis of the wild-type sequence, using an algorithm at the Stanford Denaturing High-Performance Liquid Chromatography website (http://insertion.stanford.edu/ melt.html). DHPLC heteroduplex analysis was performed using an automated HPLC instrumentation (Agilent Technologies) equipped with a Helix DNA column (Varian Inc., Netherlands). The analytical gradient was composed of Buffer A (100 mM triethylammonium acetate and $0.10 \mathrm{~mm}$ EDTA) and Buffer B (100 mM triethylammonium acetate, $0.10 \mathrm{~mm}$ EDTA and $25 \%$ acetonitrile) with a flow rate of $0.450 \mathrm{ml} \mathrm{min}^{-1}$. The injection volume of each PCR sample was $4-7 \mu$ l. The analysis time for each sample was $7 \mathrm{~min}$, including a short column wash and an equilibration step. GISTs harbouring mutations in exons 9,11 or 17 (KIT) and 11 or 17 (PDGFRA) were used as positive controls for DHPLC analysis.

\section{Protein expression analysis by immunohistochemistry}

Material and tissue microarray construction Material for protein expression analysis consisted of 522 serous ovarian carcinomas, which have been characterised previously (Lassus et al, 2003). Tissue microarrays were constructed as described previously (Kononen et al, 1998). Tissue specimens from 34 normal ovarian and 23 normal fallopian tube samples and 522 serous ovarian carcinomas were arranged in six recipient paraffin blocks. Four core tissue biopsies were obtained from each specimen (Lassus et al, 2003).

Immunohistochemistry Sections ( $5 \mu$ m thick) were cut from each block on coated slides. The sections were deparaffinised in xylene and rehydrated through graded concentrations of ethanol. The slides were pretreated with citrate buffer $(\mathrm{pH} 6.0)$ in a microwave oven for $2 \times 4 \mathrm{~min}$ and then cooled for $30 \mathrm{~min}$ before starting the staining procedure, which was performed for KIT in Dako Autostainer with the Envision System and for PDGFRA in Lab Vision Autostainer with the Ultravision System. The primary antibodies used were a polyclonal antibody against KIT (dilution 1:100; Dako, Carpinteria, CA, USA) and a polyclonal antibody against synthetic peptide derived from C-terminal of PDGFRA (dilution 1:150, Neomarkers, Lab Vision, Fremont, CA, USA). Negative controls were performed by replacing the primary antibody by normal rabbit serum. For KIT paraffin-embedded KIT-positive GISTs were used as positive controls.

The immunohistochemical analysis was evaluated by a pathologist (RB) without knowledge of the clinicopathological information. The epithelium of fallopian tubes (the normal serous epithelium of Müllerian origin) and ovarian surface epithelium (OSE) were used as a reference of normal expression for both proteins. Both membrane and cytoplasmic staining were taken into account and scored according to the intensity as follows: KIT negative, weak or strong; and PDGFRA - weak, moderate or strong.

Table I Primers used for PCR of exons of $9,11,13$ and 17 of KIT and exons II and I7 of PDGFRA

\begin{tabular}{lll}
\hline Exon & Forward primer & Reverse primer \\
\hline KIT & GTATGCCACATCCCAAGTGT & CATGACTGATATGGTAGACA \\
9 & CCAGAGTGCTCTAATGACTG & GGAAGCCACTGGAGTTCCTT \\
11 & GACATCAGTTGCCAGTTGT & TGTTTGATAACCTGACAGAC \\
13 & GCAACACTATAGTATTAAAAAG & CCTTGCAGGACTGTCAAGCA \\
17 & & \\
PDGFRA & ATGTGGAGTGAACGTTGTTGG \\
11 & CAGGGGGATGCTATTCAGC & CTAGTTCTTACTAAGCACAAGC \\
17 & & TTAAAGGAAGGAGGATGAGCC \\
\hline
\end{tabular}


Immunohistochemistry for p53 and Ki-67 was performed as described previously (Lassus et al, 2004). A polyclonal antibody against Ki-67 (1:150, clone N/A; code A0047; Dako A/S, Glostrup, Denmark) and a monoclonal antibody against p53 (1:100; clone DO-7; Dako A/S, Glostrup, Denmark) were used as primary antibodies.

\section{Fluorescence in situ hybridisation}

Paraffin-embedded samples of tumours showing distinct, strong KIT staining by immunohistochemistry were included in the FISH analysis.

Chromosome 4 was studied with a centromere-specific probe (CEP4 Spectrum Green, Vysis Inc., North Chicago, IL), and KIT gene with BAC probes (clones RP11-1106L19 and RP11-977G3). The correct probe identities were confirmed using PCR with the KIT-specific primers. The BAC-DNAs were isolated using routine techniques and labelled with DIG-Nick translation mix (Roche, Mannheim, Germany). The dual-colour hybridisations were performed as described previously (Hyytinen et al, 1994). The digoxigenin-labelled probes were detected by sheep anti-digoxigenin-rhodamine antibody (Roche, Mannheim, Germany).

Interphase nuclei were prepared as described previously (Hyytinen et al, 1994). KIT probe and chromosome 4 centromere probe were cohybridised and after hybridisation, counterstained with DAPI and viewed under a fluorescence microscopy equipped with ISIS digital image analysis system (MetaSystems). Approximately 50 interphase nuclei were analysed of each sample and percentages/subpopulation were calculated for normal and abnormal nuclei.

\section{DNA ploidy analysis}

Core tissue biopsy specimen (diameter $0.8 \mathrm{~mm}$ ) were taken from areas representing carcinoma in paraffin tissue block. The tissue cores were deparaffinised, rehydrated and DNA flow cytometry was performed as described previously (Jahkola et al, 1998).
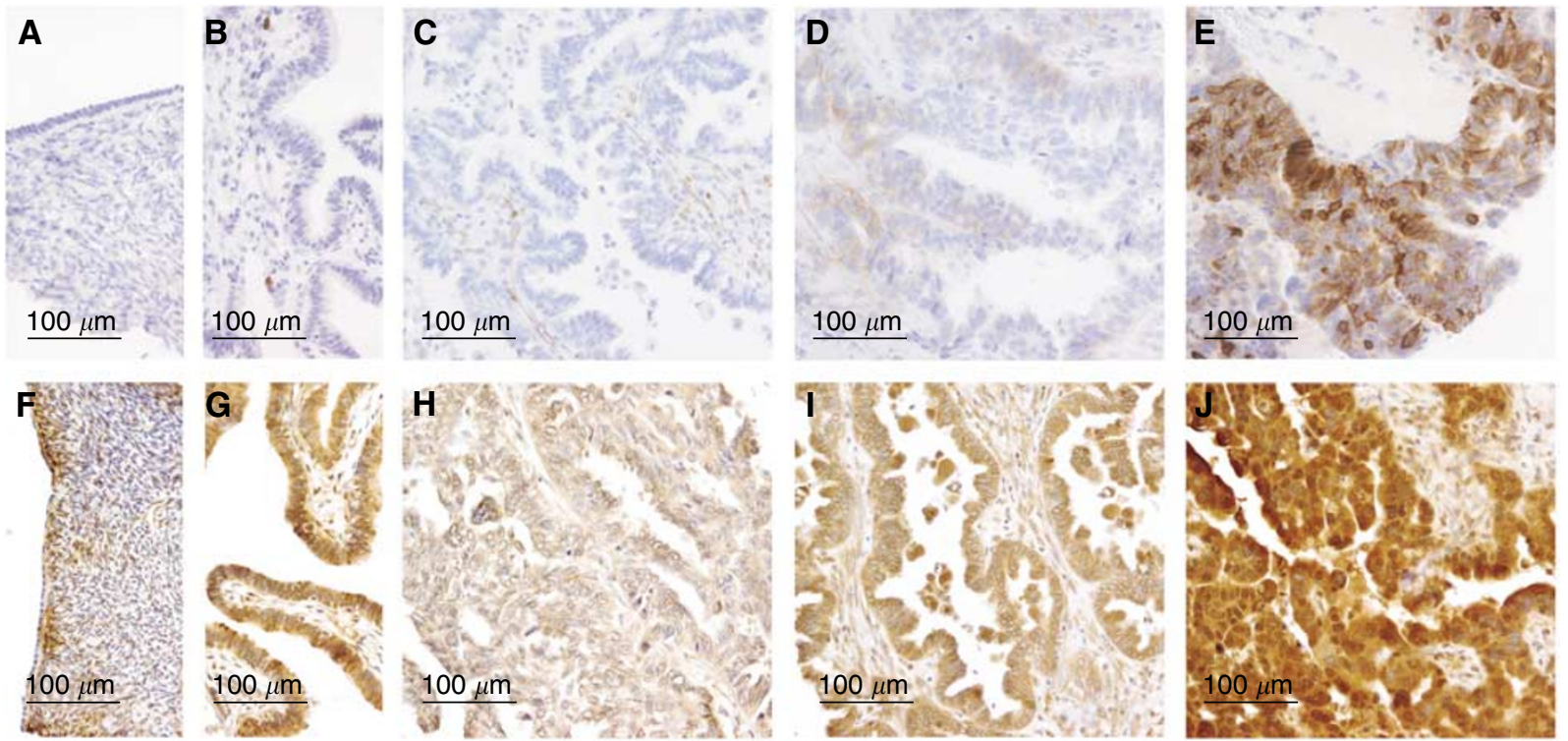

\section{Statistical analysis}

Associations between factors were analysed with the $\chi^{2}$ and Fisher's exact tests. The overall and disease-free survival curves were constructed according to the Kaplan-Meier method and compared with the log-rank test. For multivariate survival analysis Cox's proportional-hazards model was used, with backward stepwise selection procedure, and entering the following as categorial covariates: FIGO stage (stages I, II, III and IV), grade (grades 1, 2 and 3 ), age at diagnosis ( $<57$ years (median) and $\geqslant 57$ years), tumour size $(\leqslant 10 \mathrm{~cm}$ and $>10 \mathrm{~cm})$, residual tumour size ( $\leqslant 1 \mathrm{~cm}$ and $>1 \mathrm{~cm})$, ascites (presence or absence), p53 expression (normal and aberrant) and Ki-67 expression (0-10, 10-25 and $>25 \%)$. A $P$-value of 0.05 was adopted as the limit for inclusion of a covariate. All $P$-values are two-sided.

\section{RESULTS}

\section{Mutation analysis of KIT and PDGFRA}

In DNA from freshly frozen tissue samples, DHPLC analysis of at least one exon failed in approximately $5 \%$ of cases due to poor amplification of the sample DNA. Out of 14 paraffin-embedded tumours, 11 were successfully analysed. In cases of aberrant DHPLC profile, the analysis was repeated and doubtful cases were sequenced. For KIT analysis, exons 9 and 13 were sequenced in two samples. For PDGFRA analysis, exon 17 was sequenced in one sample and exon 11 in five samples. No sequence alterations were found.

\section{KIT expression and clinicopathological associations}

The epithelium of normal ovarian surface and fallopian tubes was negative for KIT protein (Figure 1A and B). In the stroma of fallopian tubes, there were single cells with strong cytoplasmic staining (Figure 1B), compatible with mast cells. The stromal cells of normal ovarian cortex showed variable, mainly weak, positivity (Figure 1A). KIT immunostaining was interpretable in $516(99 \%)$ of the 522 serous ovarian carcinomas. No staining (negative) was

Figure I Examples of KIT and PDGFRA expression by immunohistochemistry. Normal ovarian surface (A) and tubal (B) epithelium showing negative immunostaining of KIT protein. Serous ovarian carcinomas showing negative $(\mathbf{C})$, weak (D) and strong (E) staining of KIT protein. Normal OSE showing negative immunostaining of PDGFRA (F) and tubal epithelium showing moderate immunopositivity of PDGFRA (G). Serous ovarian carcinomas showing weak $(\mathbf{H})$, moderate $(\mathbf{I})$ and strong $(\mathbf{J})$ staining of PDGFRA. 
detected in 453 (88\%), weak positive immunostaining in $51(9.9 \%)$ and strong positive immunostaining in $12(2.3 \%)$ of the interpretable cases (Figure $1 \mathrm{C}-\mathrm{E}$ ).

KIT expression was associated with high tumour grade $(P<0.0001)$, advanced age $(P=0.0198)$, high proliferation index $(P=0.0004)$ and aberrant p53 status $(P=0.0053)$, but not with tumour stage, tumour size, residual tumour size or the presence of ascites (Table 2).

Patients with tumours showing KIT expression (low or high) were associated with shorter overall survival compared with cases showing negative KIT expression (Figure 2A). The 5-year overall survival rates for patients with tumours with negative, weak positive and strong positive KIT expression were $50 \%(95 \% \mathrm{CI}$, $45-55 \%), 34 \%(19-50 \%)$ and $35 \%(3-66 \%)$, respectively. When tumours with low and high KIT expression were analysed as one group (positive KIT expression), the difference was statistically significant $(P=0.0414)$. There was also a tendency for a shorter disease-free survival in patients with positive KIT expression, but the association was not statistically significant $(P=0.0875)$.

\section{PDGFRA expression and clinicopathological associations}

The epithelium of normal ovarian surface was negative for PDGFRA expression (Figure 1F), whereas the serous epithelium of fallopian tubes showed variable, moderate immunopositivity (Figure 1G). PDGFRA immunostaining was interpretable in 505
(97\%) of the 522 serous ovarian carcinomas. Weak positive immunostaining was detected in 59 (12\%), moderate immunostaining, corresponding to that of fallopian tube epithelium, in 382 $(75 \%)$ and strong immunostaining in $64(13 \%)$ of the interpretable cases (Figure $1 \mathrm{H}-\mathrm{J}$ ).

Strong PDGFRA staining was associated with high tumour grade $(P=0.0019)$, high tumour stage $(P=0.0483)$, large residual tumour size $(P=0.0330)$ and high proliferation index $(P=0.0060)$, but not with advanced age, tumour size, presence of ascites or p53 status (Table 3). PDGFRA expression was not associated with KIT expression $(P=0.13)$.

High PDGFRA expression was associated with shorter overall survival $(P=0.0353)$ (Figure $2 \mathrm{~B})$. The 5 -year overall survival rates for patients with tumours with low, moderate and high PDGFRA expression were $49 \%$ (95\% CI, $34-63 \%$ ), 51\% (46-57\%) and $31 \%$ (19-43\%), respectively. PDGFRA expression was also associated with disease-free survival $(P=0.0003)$ (Figure $2 C)$. The 5-year disease-free survival rates for patients with tumours with low, moderate and high PDGFRA expression were 90\% (95\% CI, 76$100 \%), 70 \%(64-77 \%)$ and 39\% (21-57\%), respectively.

\section{KIT and chromosome 4 copy number by FISH}

FISH analysis was successful in 10 out of 12 tumours showing high KIT expression. Six of these 10 tumours showed a normal copy number (two signals) for both chromosome 4 centromere

Table 2 Association of KIT expression with clinicopathological characteristics

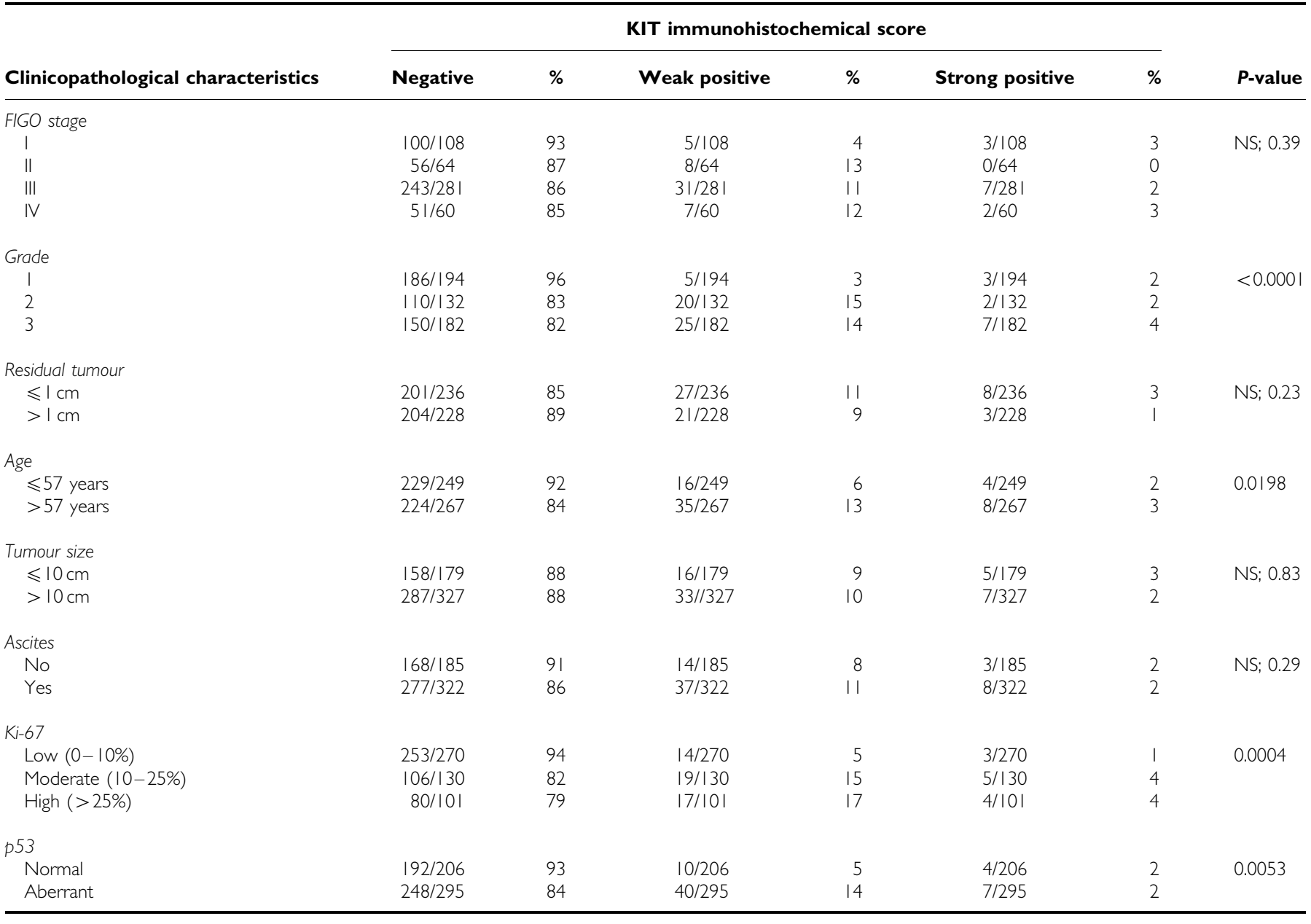

NS = not significant. 

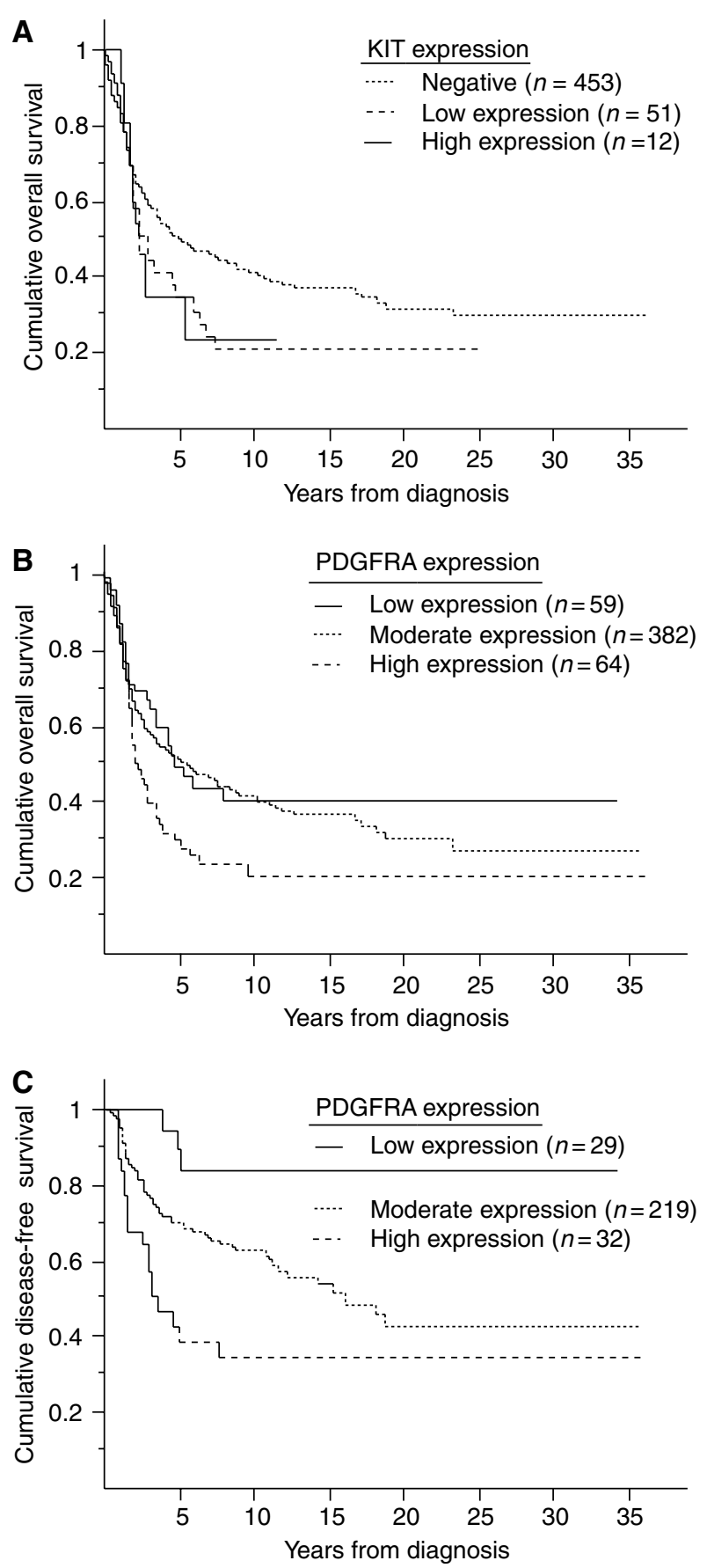

Figure 2 Overall survival in patients with serous ovarian carcinoma in relation to KIT expression (A) and PDGFRA expression (B) by immunohistochemistry. Disease-free survival in patients with serous ovarian carcinoma in relation to PDGFRA expression (C).

probe and the KIT probe. One tumour revealed a subpopulation of nuclei with tetrasomy, one tumour had a subpopulation of nuclei with five FISH-signals for both probes and one tumour showed a subpopulation with seven FISH signals for both probes (Figure 3A). One tumour showed a loss of other chromosome 4 and KIT gene (Figure 3B). No high-level amplification was observed in any of the tumours analysed. The results of FISH and ploidy analysis of these tumours are shown in Table 4.

\section{DISCUSSION}

No KIT or PDGFRA mutations were found in serous ovarian carcinomas. In our analysis, we concentrated on the juxtamembrane and catalytic domains, that is, exons $9,11,13$ and 17 of KIT and exons 11 and 17 of PDGFRA, where the activating mutations in KIT and PDGFRA have been detected (Heinrich et al, 2002; Heinrich et al, 2003). As regards KIT, our finding extends the previous observation of no mutations in 50 ovarian carcinomas of different histological types (Singer et al, 2003). As regards PDGFRA, to our knowledge, no previous reports on ovarian carcinoma exist in the literature.

KIT expression in normal ovaries and ovarian carcinomas has been addressed in several previous studies with highly variable results. At least one study (Parrott et al, 2000) reported KIT immunoreactivity in normal OSE, but most reports do not confirm this finding (Inoue et al, 1994; Tonary et al, 2000; Schmandt et al, 2003; Singer et al, 2003). In our analysis both OSE and fallopian tube epithelium, the normal serous epithelium of Müllerian origin, were negative for KIT protein. Many reports have indicated high frequency $(71-100 \%)$ of KIT expression in ovarian carcinomas (Arber et al, 1998; Parrott et al, 2000; Tonary et al, 2000), whereas others have shown lower levels of expression $(0-22 \%)$ (Inoue et al, 1994; Schmandt et al, 2003; Singer et al, 2003). We found the expression of KIT protein in $12 \%$ of serous ovarian carcinomas: $10 \%$ showed low and $2 \%$ high expression of the protein. Disparities in the findings of different studies may reflect heterogeneity in the study material as regards tumour histology and other clinicopathological parameters. More importantly, different antibodies and staining protocols have been used. Our findings are closest to those reported by Schmandt et al (2003) and Singer et al (2003), who also used the KIT CD117 polyclonal antibody (Dako), which is accepted for clinical use while assessing the KIT expression in GIST (Fletcher et al, 2002). We used the same antibody dilution and IHC protocol as routinely used in GIST diagnostics. Weak expression was found to be mainly cytoplasmic, whereas in strongly positive cases, membranous staining was also detected, presumably representing the active form of KIT protein (Tian et al, 1999; Shaw et al, 2002).

KIT expression was associated with poor histological differentiation, high patient age and poor patient outcome. The association of KIT expression with poor clinical outcome is in line with the presumed oncogenic properties of KIT. Schmandt et al (2003) also reported association of KIT expression with high tumour grade but contradictory findings exist. Tonary et al (2000) reported KIT expression to be independent of tumour grade, but associated with low tumour stage and favourable patient outcome. In that particular study, the frequency of KIT expressing tumours was very high $(71 \%)$, indicating differences in the methodology and material employed. In our study, tumours with KIT expression more often presented with high proliferation index and aberrant p53 status. Interestingly, the associations of KIT expression with grade, age, Ki-67 and p53 were independent of the degree of KIT expression (low or high). The association of KIT with high growth fraction is consistent with presumed proliferation promoting effect of KIT. However, in ovarian carcinoma cell lines, KIT inhibition by anti-KIT neutralising antibodies or the KIT inhibitor STI571 did not alter the growth rate (Shaw et al, 2002). The real biological role of KIT in ovarian carcinoma cells remains to be clarified.

The normal OSE did not express PDGFRA protein, which is in line with previous findings (Henriksen et al, 1993). However, the epithelium of fallopian tubes showed variable, moderate immunopositivity, and similar expression pattern was seen in majority $(75 \%)$ of the carcinomas. Using this as a reference, $12 \%$ of serous ovarian carcinomas showed decreased and 13\% increased PDGFRA expression. In previous reports, PDGFRA immunopositivity has varied from 5 to $100 \%$ of ovarian carcinomas (Henriksen et al, 1993; Dabrow et al, 1998; Apte et al, 2004a; Matei et al, 2004). 
Table 3 Association of PDGFRA expression with clinicopathological characteristics

\begin{tabular}{|c|c|c|c|c|c|c|c|}
\hline \multirow[b]{2}{*}{ Clinicopathological characteristics } & \multicolumn{6}{|c|}{ PDGFRA immunohistochemical score } & \multirow[b]{2}{*}{$P$-value } \\
\hline & Weak & $\%$ & Moderate & $\%$ & Strong & $\%$ & \\
\hline \multicolumn{8}{|l|}{ FIGO stage } \\
\hline 1 & $12 / 58$ & 21 & $83 / 380$ & 22 & $9 / 64$ & 14 & 0.0483 \\
\hline$\|$ & $12 / 58$ & 21 & $44 / 380$ & 12 & $10 / 64$ & 16 & \\
\hline III & $23 / 58$ & 40 & $208 / 380$ & 55 & $41 / 64$ & 64 & \\
\hline IV & $1 \mid / 58$ & 19 & $45 / 380$ & 12 & $4 / 64$ & 6 & \\
\hline \multicolumn{8}{|l|}{ Grade } \\
\hline I & $22 / 59$ & 37 & 153/375 & 41 & $13 / 63$ & 21 & 0.0019 \\
\hline 2 & | |/59 & 19 & $103 / 375$ & 27 & $15 / 63$ & 24 & \\
\hline 3 & $26 / 59$ & 44 & | | 9/375 & 32 & $35 / 63$ & 56 & \\
\hline \multicolumn{8}{|l|}{ Residual tumour } \\
\hline$\leqslant 1 \mathrm{~cm}$ & $24 / 49$ & 49 & $178 / 345$ & 51 & $20 / 60$ & 33 & 0.0330 \\
\hline$>\mathrm{l} \mathrm{cm}$ & $25 / 49$ & 51 & $167 / 345$ & 49 & $40 / 60$ & 67 & \\
\hline \multicolumn{8}{|l|}{ Age } \\
\hline$<57$ years & $29 / 59$ & 49 & $185 / 382$ & 48 & $31 / 64$ & 48 & NS; 0.99 \\
\hline$\geqslant 57$ years & $30 / 59$ & 51 & 197/382 & 52 & $33 / 64$ & 52 & \\
\hline \multicolumn{8}{|l|}{ Tumour size } \\
\hline$\leqslant 10 \mathrm{~cm}$ & $26 / 58$ & 45 & 122/377 & 32 & $23 / 61$ & 38 & NS; 0.15 \\
\hline$>10 \mathrm{~cm}$ & $32 / 58$ & 55 & $255 / 377$ & 68 & $38 / 61$ & 62 & \\
\hline \multicolumn{8}{|l|}{ Ascites } \\
\hline No & $26 / 56$ & 46 & | 30/377 & 34 & $22 / 63$ & 35 & NS; 0.22 \\
\hline Yes & $30 / 56$ & 54 & $247 / 377$ & 66 & $41 / 63$ & 65 & \\
\hline \multicolumn{8}{|l|}{$K i-67$} \\
\hline $0-10 \%$ & $39 / 57$ & 68 & $200 / 375$ & 53 & $24 / 62$ & 39 & 0.0060 \\
\hline $10-25 \%$ & $9 / 57$ & 16 & $105 / 375$ & 28 & $17 / 62$ & 27 & \\
\hline$>25 \%$ & $9 / 57$ & 16 & 70/375 & 19 & $21 / 62$ & 34 & \\
\hline \multicolumn{8}{|l|}{ p53 } \\
\hline Normal & $27 / 58$ & 47 & |55/372 & 42 & $17 / 63$ & 27 & NS; 0.053 \\
\hline Aberrant & $31 / 58$ & 53 & $217 / 372$ & 58 & $46 / 63$ & 73 & \\
\hline
\end{tabular}
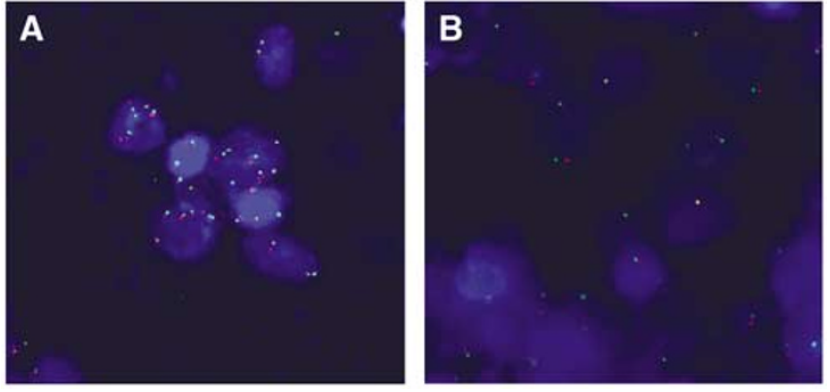

Figure 3 Examples of copy number analysis of KIT gene and chromosome 4 centromere by FISH: serous ovarian carcinomas showing a subpopulation of cells with seven signals for both probes (case 2283) (A) and a loss of other chromosome 4 and KIT gene (case 1029) (B).

Little is known about its associations with clinical para meters. Henriksen et al (1993) also found PDGFRA positivity to associate with poor overall survival. In our study, the association with disease-free survival was even stronger than that with overall survival. In line with aggressive tumour behaviour, PDGFRA expression was also associated with high tumour grade and stage, large residual tumour size and high proliferation index.
In all, 12 carcinomas presented with distinct KIT overexpression and amplification of KIT gene was considered as a possible mechanism for overexpression. However, FISH analysis revealed no gene amplification. Six tumours out of 10 showed a normal copy number, three showed polysomy and one monosomy of chromosome 4 . In two tumours showing five and seven copies of chromosome 4, the tumour cells were diploid/hyperdiploid, indicating a relative gain of chromosome 4. In two cases, there was a relative loss of chromosome 4: one with monosomy of chromosome 4 and diploid DNA and the other with two copies of chromosome 4 and hypertetraploid DNA. KIT gene is located at the proximal part of chromosome arm $4 \mathrm{q}(4 \mathrm{q} 11-12)$. According to cytogenetic and comparative genomic hybridisation studies, gain of chromosome 4 is a very rare event in ovarian carcinoma. The relative gain of chromosome 4 we observed in two out of 10 tumours is an unexpected finding (http://cgap.nci.nih.gov/ Chromosomes/RecurrentAberrations; http://ethesis.helsinki.fi/ julkaisut/laa/kliin/vk/lassus/) and may account for the overexpression of KIT in these cases. Interstitial chromosomal deletion on $4 \mathrm{q} 12$ yielding active fusion protein FIPIL1-PDGFRA plays a causal role in a portion of idiopathic hypereosinophilia syndrome and chronic eosinophilic leukaemia cases that can successfully be treated with imatinib mesylate (Coutre and Gotlib, 2004). Interestingly, loss of chromosomal material from $4 \mathrm{q}$ is frequent in serous ovarian carcinoma (reviewed in http://ethesis.helsinki.fi/ julkaisut/laa/kliin/vk/lassus/) and gain-of-function deletion is an intriguing alternative mechanism for PDGFRA overexpression. 
Table 4 Copy number of KIT and chromosome 4, ploidy, expression of Ki-67 and p53 in serous ovarian carcinomas showing high expression of KIT protein

\begin{tabular}{|c|c|c|c|c|c|}
\hline Case & KIT & Chr. 4 & Ploidy & Ki-67 & p53 \\
\hline 7 & 2 & 2 & Diploid & Moderate & Normal \\
\hline 489 & 2 & 2 & $45 \%$ diploid, $55 \%$ hyperdiploid $(\mathrm{DI}=1.45)$ & High & Aberrant \\
\hline 859 & $2 / 5$ & $2 / 5$ & Diploid & High & Aberrant \\
\hline 1029 & 1 & । & Diploid & High & Normal \\
\hline 1164 & 2 & 2 & Diploid & High & Aberrant \\
\hline 2013 & 2 & 2 & Diploid & Low & Normal \\
\hline 2120 & $2 / 4$ & $2 / 4$ & $46 \%$ diploid, $54 \%$ hyperdiploid $(\mathrm{DI}=1.84$ ) & Moderate & Aberrant \\
\hline 2175 & $\mathrm{NI}$ & $\mathrm{NI}$ & $50 \%$ hyperdiploid $(\mathrm{DI}=1.5), 50 \%$ hypertetraploid $(\mathrm{DI}=3)$ & Low & $\mathrm{NI}$ \\
\hline 2280 & 2 & 2 & Hypertetraploid $(\mathrm{DI}=2.19)$ & Moderate & Aberrant \\
\hline 2283 & $2 / 7$ & $2 / 7$ & Hyperdiploid (DI=1.73) & Moderate & Aberrant \\
\hline 2381 & $\mathrm{NI}$ & $\mathrm{NI}$ & Diploid & Moderate & Aberrant \\
\hline 2636 & 2 & 2 & Diploid & Low & Normal \\
\hline
\end{tabular}

$\mathrm{NI}=$ not informative; $\mathrm{DI}=\mathrm{DNA}$ index; categories: 1 - 1.2 = diploid, $1.21-1.90=$ hyperdiploid, $1.91-2.1$ = tetraploid, 2.11 - = hypertetraploid.

The lack of KIT and PDGFRA mutations seems discouraging as regards potential usefulness of imatinib mesylate in serous ovarian carcinoma. In GISTs (KIT and PDGFRA mutations), breast carcinoma (HER-2 amplification) and lung cancer (EGFR mutation), targeted therapy has yielded best results in cases with activating mutation or amplification of the respective gene (Vogel et al, 2002; Heinrich et al, 2003; Lynch et al, 2004). However, in our study, both KIT and PDGFRA expression were associated with aggressive tumour characteristics, such as high tumour grade, high proliferation index and poor patient outcome, suggesting them a role in the pathophysiology of at least a subset of serous ovarian carcinomas. Accordingly, imatinib mesylate has inhibited growth of ovarian cancer cells through PDGFRA and Akt inactivation (Matei et al, 2004), and combination therapy of imatinib-paclitaxel has impaired progression of ovarian cancer in peritoneal cavity of nude mice and lead to increased apoptosis of tumour-associated endothelial cells (Apte et al, 2004b). The possible usefulness of imatinib mesylate in the treatment of ovarian carcinoma can only be resolved in clinical trials. If such were to be conducted, KIT or PDGFRA overexpression, and not mutational status of the genes, would seem as appropriate criteria for selection of patients.

\section{ACKNOWLEDGEMENTS}

This study was supported by grants from Helsinki University Central Hospital, Foundation for the Finnish Cancer Institute and Juselius Foundation. We thank Gynel Arifdshan for excellent technical assistance.

\section{REFERENCES}

Apte SM, Bucana CD, Killion JJ, Gershenson DM, Fidler IJ (2004a) Expression of platelet-derived growth factor and activated receptor in clinical specimens of epithelial ovarian cancer and ovarian carcinoma cell lines. Gynecol Oncol 93: 78-86

Apte SM, Fan D, Killion JJ, Fidler IJ (2004b) Targeting the platelet-derived growth factor receptor in antivascular therapy for human ovarian carcinoma. Clin Cancer Res 10: 897-908

Arber DA, Tamayo R, Weiss LM (1998) Paraffin section detection of the ckit gene product (CD117) in human tissues: value in the diagnosis of mast cell disorders. Hum Pathol 29: $498-504$

Coutre S, Gotlib J (2004) Targeted treatment of hypereosinophilic syndromes and chronic eosinophilic leukemias with imatinib mesylate. Semin Cancer Biol 14: 307-315

Dabrow MB, Francesco MR, McBrearty FX, Caradonna S (1998) The effects of platelet-derived growth factor and receptor on normal and neoplastic human ovarian surface epithelium. Gynecol Oncol 71: $29-37$

Demetri GD, von Mehren $M$, Blanke CD, Van den Abbeele AD, Eisenberg B, Roberts PJ, Heinrich MC, Tuveson DA, Singer S, Janicek M, Fletcher JA, Silverman SG, Silberman SL, Capdeville R, Kiese B, Peng B, Dimitrijevic S, Druker BJ, Corless C, Fletcher CD, Joensuu H (2002) Efficacy and safety of imatinib mesylate in advanced gastrointestinal stromal tumors. $N$ Engl $J$ Med 347: $472-480$

Fletcher CD, Berman JJ, Corless C, Gorstein F, Lasota J, Longley BJ, Miettinen M, O'Leary TJ, Remotti H, Rubin BP, Shmookler B, Sobin LH, Weiss SW (2002) Diagnosis of gastrointestinal stromal tumors: a consensus approach. Hum Pathol 33: 459-465

Fletcher JA (2004) Role of KIT and platelet-derived growth factor receptors as oncoproteins. Semin Oncol 31: 4-11
Heinrich MC, Blanke CD, Druker BJ, Corless CL (2002) Inhibition of KIT tyrosine kinase activity: a novel molecular approach to the treatment of KIT-positive malignancies. J Clin Oncol 20: 1692-1703

Heinrich MC, Corless CL, Demetri GD, Blanke CD, von Mehren M, Joensuu H, McGreevey LS, Chen CJ, Van den Abbeele AD, Druker BJ, Kiese B, Eisenberg B, Roberts PJ, Singer S, Fletcher CD, Silberman S, Dimitrijevic S, Fletcher JA, Singer G, Schraml P, Belgard C, Raggi A, Dirnhofer S, Went P, Mihatsch MJ, Moch H (2003) Kinase mutations and imatinib response in patients with metastatic gastrointestinal stromal tumor. J Clin Oncol 21: $4342-4349$

Heintz AP, Odicino F, Maisonneuve P, Beller U, Benedet JL, Creasman WT, Ngan HY, Sideri M, Pecorelli S (2001) Carcinoma of the ovary. J Epidemiol Biostat 6: $107-138$

Henriksen R, Funa K, Wilander E, Backstrom T, Ridderheim M, Oberg K (1993) Expression and prognostic significance of platelet-derived growth factor and its receptors in epithelial ovarian neoplasms. Cancer Res 53: $4550-4554$

Hyytinen E, Visakorpi T, Kallioniemi A, Kallioniemi OP, Isola JJ (1994) Improved technique for analysis of formalin-fixed, paraffin-embedded tumors by fluorescence in situ hybridization. Cytometry 16: $93-99$

Inoue M, Kyo S, Fujita M, Enomoto T, Kondoh G (1994) Coexpression of the c-kit receptor and the stem cell factor in gynecological tumors. Cancer Res 54: 3049-3053

Jahkola T, Toivonen T, Virtanen I, von Smitten K, Nordling S, von Boguslawski K, Haglund C, Nevanlinna H, Blomqvist C (1998) Tenascin$\mathrm{C}$ expression in invasion border of early breast cancer: a predictor of local and distant recurrence. Br J Cancer 78: 1507 - 1513

Klemi PJ, Pylkkanen L, Kiilholma P, Kurvinen K, Joensuu H (1995) p53 protein detected by immunohistochemistry as a prognostic factor in patients with epithelial ovarian carcinoma. Cancer 76: 1201-1208 
Kononen J, Bubendorf L, Kallioniemi A, Barlund M, Schraml P, Leighton S, Torhorst J, Mihatsch MJ, Sauter G, Kallioniemi OP (1998) Tissue microarrays for high-throughput molecular profiling of tumor specimens. Nat Med 4: 844-847

Lassus H, Laitinen MP, Anttonen M, Heikinheimo M, Aaltonen LA, Ritvos O, Butzow R (2001) Comparison of serous and mucinous ovarian carcinomas: distinct pattern of allelic loss at distal $8 \mathrm{p}$ and expression of transcription factor GATA-4. Lab Invest 81: 517-526

Lassus H, Leminen A, Lundin J, Lehtovirta P, Butzow R (2003) Distinct subtypes of serous ovarian carcinoma identified by p53 determination. Gynecol Oncol 91: 504-512

Lassus H, Leminen A, Vayrynen A, Cheng G, Gustafsson J-Å, Isola J, Butzow R (2004) ERBB2 amplification is superior to protein expression status in predicting patient outcome in serous ovarian carcinoma. Gynecol Oncol 92: 31-39

Lynch TJ, Bell DW, Sordella R, Gurubhagavatula S, Okimoto RA, Brannigan BW, Harris PL, Haserlat SM, Supko JG, Haluska FG, Louis DN, Christiani DC, Settleman J, Haber DA (2004) Activating mutations in the epidermal growth factor receptor underlying responsiveness of non-small-cell lung cancer to gefitinib. N Engl J Med 350: 2129-2139

Makar AP, Baekelandt M, Trope CG, Kristensen GB (1995) The prognostic significance of residual disease, FIGO substage, tumor histology, and grade in patients with FIGO stage III ovarian cancer. Gynecol Oncol 56: $175-180$

Matei D, Chang DD, Jeng MH (2004) Imatinib mesylate (Gleevec) inhibits ovarian cancer cell growth through a mechanism dependent on plateletderived growth factor receptor alpha and Akt inactivation. Clin Cancer Res 10: $681-690$

Obata K, Morland SJ, Watson RH, Hitchcock A, Chenevix-Trench G, Thomas EJ, Campbell IG (1998) Frequent PTEN/MMAC mutations in endometrioid but not serous or mucinous epithelial ovarian tumors. Cancer Res 58: 2095-2097

Parrott JA, Kim G, Skinner MK (2000) Expression and action of kit ligand/ stem cell factor in normal human and bovine ovarian surface epithelium and ovarian cancer. Biol Reprod 62: 1600-1609
Risch HA, Marrett LD, Jain M, Howe GR (1996) Differences in risk factors for epithelial ovarian cancer by histologic type. Results of a case - control study. Am J Epidemiol 144: 363-372

Schmandt RE, Broaddus R, Lu KH, Shvartsman H, Thornton A, Malpica A, Sun C, Bodurka DC, Gershenson DM (2003) Expression of c-ABL, c-KIT, and platelet-derived growth factor receptor-beta in ovarian serous carcinoma and normal ovarian surface epithelium. Cancer 98: $758-764$

Schwartz DR, Kardia SL, Shedden KA, Kuick R, Michailidis G, Taylor JM, Misek DE, Wu R, Zhai Y, Darrah DM, Reed H, Ellenson LH, Giordano TJ, Fearon ER, Hanash SM, Cho KR (2002) Gene expression in ovarian cancer reflects both morphology and biological behavior, distinguishing clear cell from other poor-prognosis ovarian carcinomas. Cancer Res 62: $4722-4729$

Shaw TJ, Keszthelyi EJ, Tonary AM, Cada M, Vanderhyden BC, Macdonald EA, Faught W, Senterman MK (2002) Cyclic AMP in ovarian cancer cells both inhibits proliferation and increases c-KIT expression. Exp Cell Res 273: $95-106$

Singer G, Schraml P, Belgard C, Raggi A, Dirnhofer S, Went P, Mihatsch MJ, Moch H (2003) KIT in ovarian carcinoma: disillusion about a potential therapeutic target. J Natl Cancer Inst 95: 1009-1010

Tapper J, Butzow R, Wahlstrom T, Seppala M, Knuutila S (1997) Evidence for divergence of DNA copy number changes in serous, mucinous and endometrioid ovarian carcinomas. Br J Cancer 75: $1782-1787$

Tian Q, Frierson Jr HF, Krystal GW, Moskaluk CA (1999) Activating c-kit gene mutations in human germ cell tumors. Am J Pathol 154: $1643-1647$

Tonary AM, Macdonald EA, Faught W, Senterman MK, Vanderhyden BC (2000) Lack of expression of c-KIT in ovarian cancers is associated with poor prognosis. Int I Cancer 89: $242-250$

Vogel CL, Cobleigh MA, Tripathy D, Gutheil JC, Harris LN, Fehrenbacher L, Slamon DJ, Murphy M, Novotny WF, Burchmore M, Shak S, Stewart SJ, Press M (2002) Efficacy and safety of trastuzumab as a single agent in first-line treatment of HER2-overexpressing metastatic breast cancer. J Clin Oncol 20: 719-726 